\title{
Uji Banding Citra Film Terhadap Computed Radiography (CR)
}

\author{
Febria Anita $^{1 *}$, Desty Anggita Tunggadewi ${ }^{1}$ \\ ${ }^{1}$ Program Studi Fisika, Universitas Nasional, Jl. Sawo Manila, Pejaten, Pasar Minggu Jakarta \\ Selatan 12520 \\ *Korespondensi penulis: febria.anita85@gmail.com
}

\begin{abstract}
Abstrak. Tujuan dari penelitian ini adalah menentukan karakteristik citra imaging dengan film melalui pengolahan citra dari keluaran pesawat computed radiography (CR) menggunakan pengolahan citra digital. Dari nilai densitas yang dihasilkan pada CR tampak pada grafik menunjukkan CR lebih linier dibandingkan film. Pada penggunaan faktor eksposi dengan tegangan $80 \mathrm{kV} 20 \mathrm{mAs}$ CR masih bisa mengkonstruksi citra sedangkan pada film sudah tidak mengkonstruksi citra dengan OD lebih dari 3,52. Penggunaan faktor eksposi dengan tegangan tetap menghasilkan nilai deviasi menurun pada setiap step, untuk penggunaan arus tetap nilai deviasi mengalami kenaikan. Pada kondisi tinggi film radiografi sudah tidak bisa mengkonstruksi densitas citra.
\end{abstract}

Kata Kunci : nilai densitas, film, computed radiology, variasi faktor eksposi.

\begin{abstract}
The purpose of this study to determine the characteristics of imaging images with film image processing from the output of computed radiography $(C R)$ using digital image processing. Due to the Density Values that was shown at Computed Radiography in which stated on graphics, informed that CR more linier than Film. By using the Expotion Factors with the voltage at $80 \mathrm{Kv}$ $20 \mathrm{mAs}$, CR still constructed the Images, while at FILM has been not constructed The Images with OD more than 3,52. By using the Expotion Factors with the steady voltages, would produce Density values remain lower in each step, but for the using fixed stream, the density values has shown higher escalation point. In high condition film, the radiography could not contruct the Image Densities.
\end{abstract}

Keywords: density value, computed radiography, expotion factor variation.

\section{PENDAHULUAN}

Computed radiography $(C R)$ adalah proses merubah sistem analog pada konvensional radiografi menjadi digital radiografi [1]. Pada sistem Computed Radiography data analog dikonversi ke dalam data digital pada saat tahap pembangkitan energi yang terperangkap di dalam imaging plate dengan menggunakan laser, selanjutnya data digital berupa sinyal-sinyal ditangkap oleh Photo Multiplier Tube (PMT) kemudian cahaya tersebut digandakan dan diperkuat intensitasnya setelah itu di ubah menjadi sinyal elektrik yang akan di konversi kedalam data digital oleh Analog Digital Converter $(A D C)$. CR memiliki banyak kelebihan dibandingkan dengan radiografi konvensional yaitu mampu mengolah gambar yang dicetak dalam film sesuai dengan keinginan tanpa adanya pengambilan gambar ulang. Pada sistem CR data analog di konversi kedalam data digital Analog Digital Converter (ADC) [2]

Konvensional radiografi dihasilkan oleh sinar-x film yang telah melalui beberapa proses yang berkesinambungan, sehingga apabila tejadi kesalahan pada salah satu atau beberapa bagian dari proses tersebut maka akan berpengaruh langsung dengan tampilan gambar. Untuk memperbaikinya proses harus diulang secara keseluruhan dari awal. Sedangkan pada CR gambar ditampilkan dengan monitor komputer yang didukung oleh software 
khusus untuk medical imaging, sehingga gambar bisa diperbaiki pada tampilannya yang bertujuan untuk memudahkan menegakkan diagnosa suatu penyakit [3].

Teknik pemeriksaan untuk CR dan konvensional sama menggunakan sinar-x, objek dan faktor ekposi sehingga menghasilkan gambaran. Bagian film yang mendapatkan sinar-x lebih sedikit nantinya akan berwarna putih sementara bagian film yang mendapatkan sinar-X lebih banyak akan berwarna hitam disebut kulitas gambaran [4]. Densitas film radiografi sangat bergantung pada warna, intensitas dan jarak filter safe light yang digunakan pada saat pemrosesan film. Filter safe light merah dan intensitas 2.4 lux pada jarak $100 \mathrm{~cm}$ dan $150 \mathrm{~cm}$ paling aman digunakan pada pemrosesan film radiografi, sedangkan warna hijau dan intensitas 2 lux pada jarak $150 \mathrm{~cm}$ aman juga digunakan untuk pemrosesan film, namun berbeda halnya untuk warna biru semua intensitas dan jarak yang digunakan tidak aman untuk pemrosesan film yang ditandai dengan nilai densitas pada base fog berkisar antara $0.25-0.31$, sedangkan toleransi yang diijinkan adalah $0.10-0.22$ [5].

Telah dilakukan penelitian tentang pengaruh perubahan faktor eksposi pada pemeriksaan radiografi abdomen menggunakan CR terhadap kualitas radiograf dan paparan radiasi. Pengaruh perubahan faktor eksposi terhadap kualitas radiograf diperoleh melalui pengukuran densitas radiograf setelah sinar-X menembus stepwedge dan obyek phantom abdomen [6]. Nilai sensitifitas paling baik pada respon Image Plate CR dengan merek $i$ CRco diperoleh dengan menggunakan faktor eksposi tegangan $90 \mathrm{kV}$ dengan arus 6.3 mAs dan $8 \mathrm{mAs}$ [7].

\section{METODE DAN BAHAN}

Pada tahap ini pengambilan data dilakukan dengan penyinaran sinar-X ke phantom tulang dan stepwedge menggunakan pesawat CR dan konvensional. Peneliti melakukan penyinaran menggunakan 2 jenis variasi faktor eksposi, yaitu tegangan tetap dan arus naik, tegangan naik arus tetap. Gambar 1 di bawah ini merupakan skema Pengambilan data penelitian, dilakukan dengan mengeksposi kaset berisi film dengan phantom sebagai objek, jarak antara phantom dengan pesawat X-Ray $100 \mathrm{~cm}$.

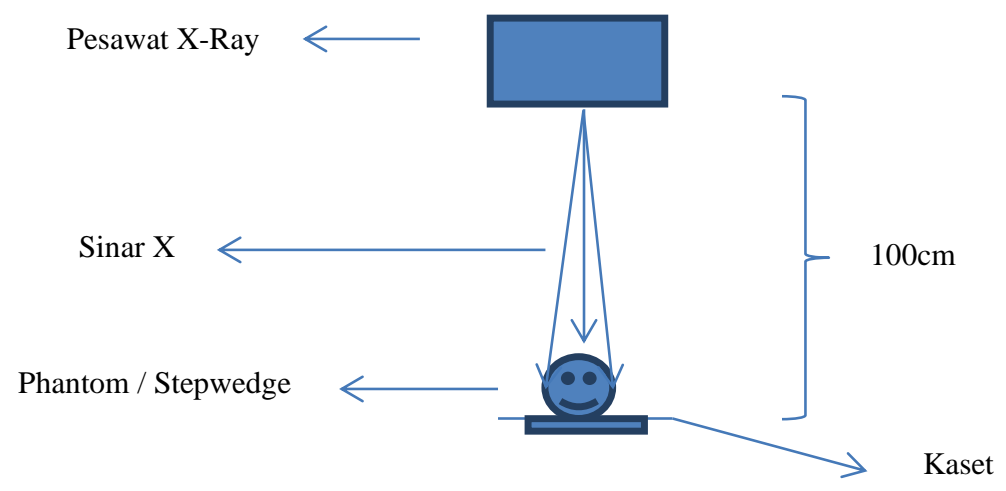

GAMBAR 1. Ilustrasi penyinaran.

Data yang akan dianalisa pada penelitian ini adalah hasil analisis pengukuran nilai densitas menggunakan densitometer terhadap film dengan CR dengan phantom, stepwedge. Pengolahan data dilakukan dengan aplikasi computer Microsoft Excel 2010. Dalam penelitian ini data yang berupa nilai densitas setiap titik pengukuran diolah dan disajikan secara deskriptif dalam bentuk tabel dan grafik. Dari data nilai densitas terukur kemudian dibuat grafik hubungan antara variasi $\mathrm{kV}$ dan $\mathrm{mAs}$ dengan kurva karakteristik terhadap nilai densitas terukur. Gambar 2 merupakan diagram alir penelitian mulai dari persiapan alat sampai dengan pengolahan data. 


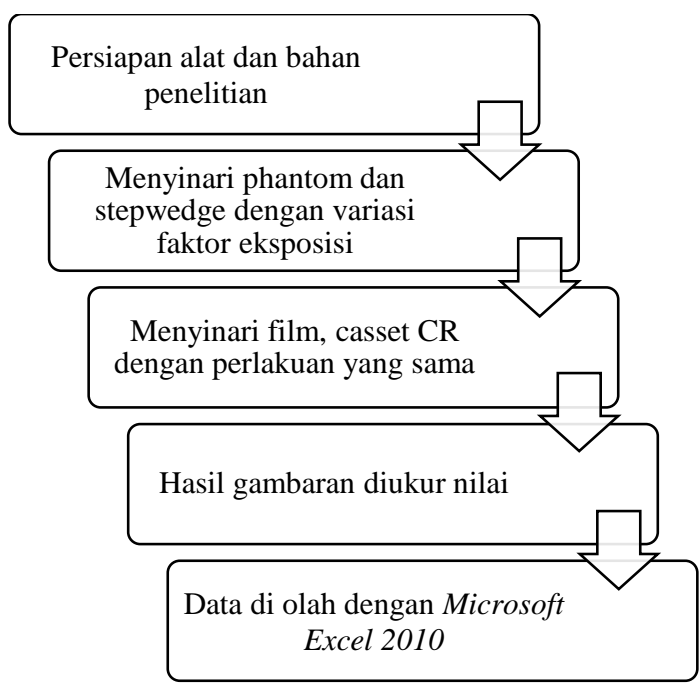

GAMBAR 2. Diagram alir penelitian

Adapun alat dan bahan penelitian ini adalah sebagai berikut:

TABEL 1. alat dan bahan penelitian

\begin{tabular}{l}
\hline Jenis Alat \\
\hline Pesawat X-Ray Type MUX-10 S/N 2X40094220 Merk \\
Shimadzu. \\
Gambar Alat ini digunakan untuk menyinari phantom \\
tulang dan Stepwedge seperti gambar 3 di bawah ini.
\end{tabular}

Phantom dari tulang Kambing dengan lapisan Lilin. Phantom merupakan objek pengganti dari manusia untuk pengambilan data dengan menyinari phantom dengan sinar X seperti gambar 4 dibawah ini

Computed Radiography DryView 5950 Laser printer Computed Radiography adalah satu sistem atau proses untuk mengubah sistem analog pada konvensional radiografi menjadi digital radiografi, dengan menggunakan photostimulable untuk mengakuisisi data dan menampilkan parameter dari gambaran yang akan dimanipulasi oleh computer seperti gambar 5 dibawah ini

Kaset pada Computed Radiography terbuat dari carbon fiber dan bagian belakang terbuat dari almunium, kaset ini berfungsi sebagai pelindung dari Imaging Plate seperti gambar 6 dibawah ini.
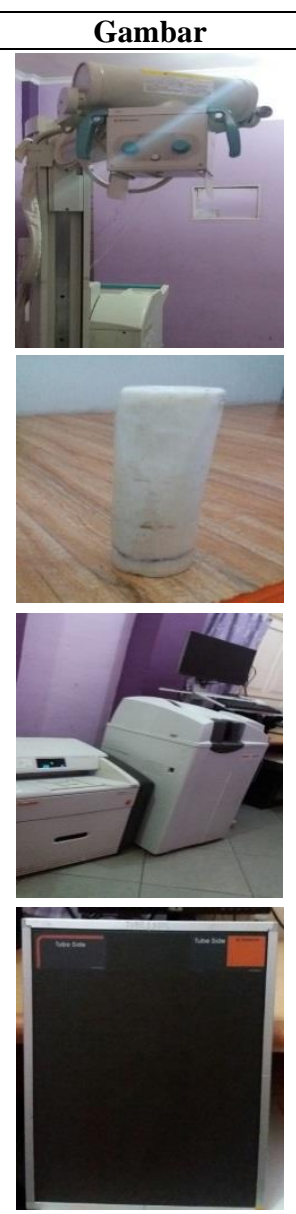
Apron adalah peralatan yang digunakan sebagai bahan pelindung terhadap radiasi sinar-X. Fungsi sebagai pelindung terhadap radiasi sinar-X ditunjukkan dengan daya serapnya terhadap radiasi sinar-X. Prinsip perisai radiasi adalah mengurangi fluks radiasi dibalik perisai seperti gambar 7 dibawah ini

Densitometer Merk X-Rite No seri : 30IX/005102

Densitometer adalah sebuah alat yang mempunyai sensor foto elektrik yang mengukur jumlah cahaya yang ditransmisikan melalui selembar film seperti gambar 8 dibawah ini.

Step wedge adalah sebuah benda yang terbuat dari Al dengan bentuk yang bertingkat - tingkat dan ketebalan yang berbeda - beda. Apabila Step Wedge dieksposi oleh sinar-X maka akan dihasilkan densitas yang berbeda pada tiap tingkatan seperti gambar 9 dibawah ini.

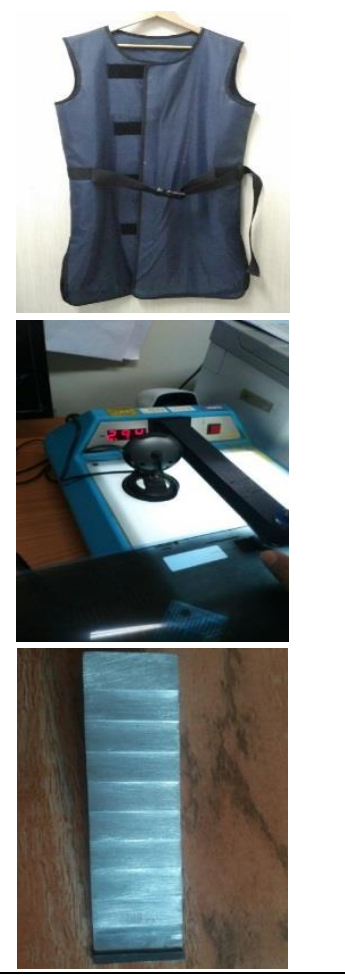

\section{HASIL DAN PEMBAHASAN}

Penelitian ini menghasilkan data pengukuran densitas gambaran menggunakan film dengan CR dengan menggunakan densitometer, penelitian ini mengambil sampel pada phantom, stepwedge dengan ukuran, bentuk dan ketebalan yang sama. Densitas radiasi yang terukur sangat bervarasi tergantung pada besarnya faktor eksposi yang diekspos ke film manual dan $\mathrm{CR}$, Peneliti melakukan pengukuran pada stepwedge sebagai pembanding nilai densitas.

Pengukuran pertama pada film dan CR dengan obyek stepwedge menggunakan variasi faktor eksposi sebagai berikut. Tabel 2 merupakan hasil pengukuran densitas gambaran menggunakan variasi faktor eksposi pada stepwedge.

TABEL 2. Perbandingan hasil nilai deviasi antara film dengan CR pada stepwedge.

\begin{tabular}{ccccccc}
\hline \multirow{2}{*}{ STEP } & \multicolumn{7}{c}{ Nilai Deviasi (\%) } \\
\cline { 2 - 7 } & $\mathbf{5 0 k V}$ & $\mathbf{6 0 k V}$ & $\mathbf{7 0 k V}$ & $\mathbf{8 0 k V}$ & $\mathbf{7 0 k v}$ & $\mathbf{7 0 k V}$ \\
& $\mathbf{2 0 m A s}$ & $\mathbf{2 0 m A s}$ & $\mathbf{2 0 m A S}$ & $\mathbf{2 0 m A S}$ & $\mathbf{5 m A S}$ & $\mathbf{1 0 m A S}$ \\
\hline $1(5 \mathrm{~cm})$ & 0.72 & 0.68 & 0.91 & 0.89 & 0.66 & 0.1 \\
$2(4,5 \mathrm{~cm})$ & 0.61 & 0.59 & 0.86 & 0.85 & 0.62 & 0.08 \\
$3(4 \mathrm{~cm})$ & 0.54 & 0.55 & 0.82 & 0.8 & 0.57 & 0.14 \\
$4(3,5 \mathrm{~cm})$ & 0.49 & 0.52 & 0.79 & 0.75 & 0.51 & 0.15 \\
$5(3 \mathrm{~cm})$ & 0.4 & 0.46 & 0.74 & 0.68 & 0.48 & 0.21 \\
$6(2,5 \mathrm{~cm})$ & 0.28 & 0.38 & 0.69 & 0.63 & 0.43 & 0.27 \\
$7(2 \mathrm{~cm})$ & 0.21 & 0.38 & 0.63 & 0.53 & 0.37 & 0.39 \\
$8(1,5 \mathrm{~cm})$ & 0.19 & 0.32 & 0.55 & 0.45 & 0.32 & 0.41 \\
$9(1 \mathrm{~cm})$ & 0.1 & 0.25 & 0.48 & 0.33 & 0.27 & 0.38 \\
$10(0,5 \mathrm{~cm})$ & -0.03 & 0.22 & 0.35 & 0.33 & 0.17 & 0.32 \\
\hline
\end{tabular}

Dari tabel 2 dapat terlihat kenaikan pada nilai deviasi dengan peningkatan tegangan dan kuat arus tetap. Ketika menggunakan tegangan tetap dengan arus meningkat didapatkan nilai deviasi mengalami penurunan. 
Dari gambar 3 memperlihatkan sebaran nilai densitas variasi faktor ekspos pada 10 titik dengan kisaran nilai densitas untuk film dengan CR nilai deviasi terendah -0,3. Grafik yang menunjukkan daerah pada kurva karakteristik terdapat pada tegangan $70 \mathrm{kV} 10 \mathrm{mAs}$.

Pengukuran kedua pada film dan Computed Radiography dengan objek phantom dari tulang Kambing dengan lapisan Lilin menggunakan variasi faktor eksposi sebagai berikut.

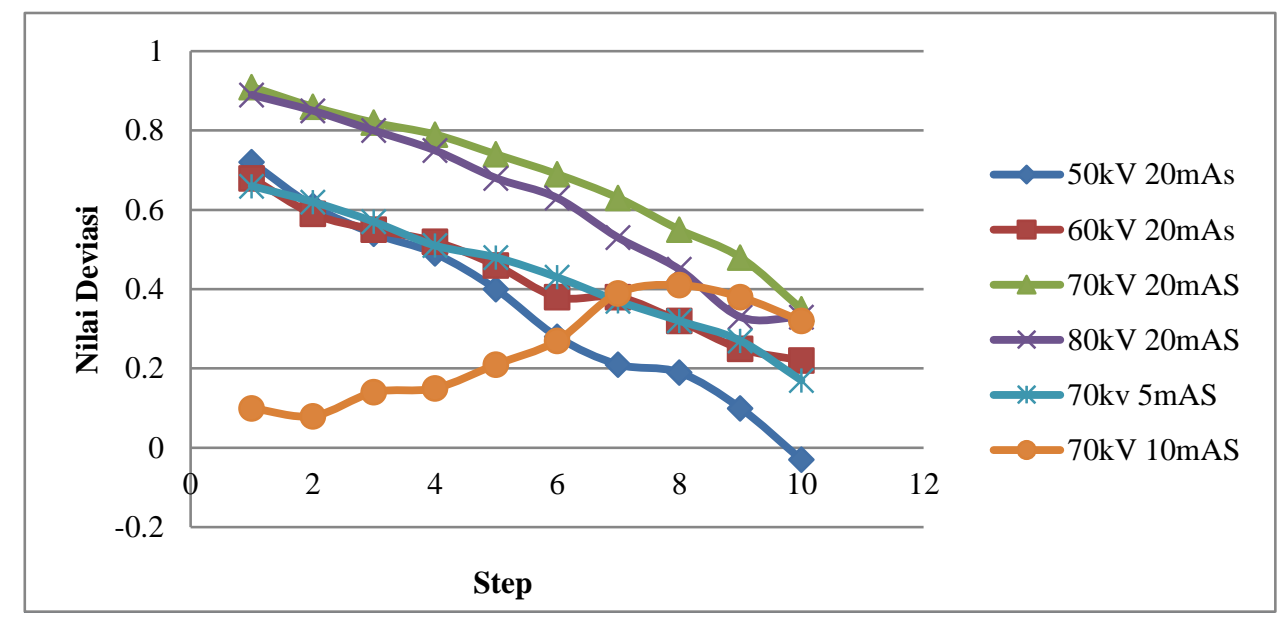

GAMBAR 3. Hasil pengukuran pada stepwedge denngan perbandingan nilai deviasi terhadap variasi faktor ekposi antara film dengan CR

Tabel 3 merupakan hasil pengukuran densitas gambaran menggunakan variasi faktor eksposi pada phantom.

TABEL 3. Perbandingan Hasil Nilai Deviasi antara Film dengan CR pada Phantom .

\begin{tabular}{ccccc}
\hline (kV - mAs) & Titik Ke- & Film $(\mathbf{O D})$ & CR $(\mathbf{O D})$ & Deviasi (\%) \\
\hline $50-20$ & 1 & 2.69 & 0.24 & 0.91 \\
& 2 & 2.77 & 0.92 & 0.67 \\
& 3 & 2.86 & 1.15 & 0.60 \\
\hline $60-20$ & 1 & 3.12 & 0.27 & 0.91 \\
& 2 & 3.29 & 0.89 & 0.73 \\
& 3 & 3.49 & 1.04 & 0.70 \\
\hline $70-20$ & 1 & 3.49 & 0.28 & 0.92 \\
& 2 & 3.49 & 0.85 & 0.76 \\
& 3 & 3.49 & 1.15 & 0.67 \\
\hline $80-20$ & 1 & 3.49 & 0.37 & 0.89 \\
& 2 & 3.52 & 1.07 & 0.70 \\
& 3 & 3.52 & 1.47 & 0.58 \\
\hline $70-5$ & 1 & 3.24 & 1.72 & 0.47 \\
& 2 & 3.26 & 1.99 & 0.39 \\
& 3 & 3.39 & 2.11 & 0.38 \\
\hline $70-10$ & 1 & 3.49 & 1.68 & 0.52 \\
& 2 & 3.52 & 1.99 & 0.43 \\
& 3 & 3.53 & 2.06 & 0.42 \\
\hline
\end{tabular}

Dari tabel 3 merupakan hasil nilai deviasi dari film dan CR pada phantom dapat terlihat kenaikan pada nilai deviasi dengan peningkatan tegangan dan kuat arus tetap mengalami penurunan nilai deviasi pada variasi $80 \mathrm{kV} 20 \mathrm{mAs} 0,89 \%$.

Pada gambar 4, terlihat jelas pada film kenaikan tegangan dan arus mempengaruhi nilai densitas yang dihasilkan, semakin tinggi faktor eksposi yang digunakan pada penyinaran film densitas tinggi, film radiografi sudah tidak bisa merekonstruksi densitas citra. Nilai 
densitas yang dihasilkan dari penyinaran stepwedge nilai deviasi didapat dari faktor eksposi $70 \mathrm{kV}$ dan $10 \mathrm{mAs}$ pada film dan CR pada setiap step 1, nilai mulai dari $0,10 \%$ terbesar sampai $0.32 \%$ terkecil. Ketika dilakukan penurunan arus didapat nilai deviasi dari faktor eksposi $70 \mathrm{kV}$ dan $5 \mathrm{mAs}$ pada film dan CR pada setiap step 1, nilai mulai dari $0,66 \%$ terbesar sampai $0.17 \%$ terkecil. Dengan melakukan peningkatan nilai tegangan dan arus hasil nilai deviasi dari film dan CR dapat terlihat kenaikan deviasi pada variasi $80 \mathrm{kV} 20 \mathrm{mAs} 0,89 \%$.

Nilai densitas yang dihasilkan dari penyinaran tulang kambing dilapisi lilin dari faktor eksposi $70 \mathrm{kV}$ dan $10 \mathrm{mAs}$ pada film dan CR pada titik tergelap dititik 1 nilai deviasi $0.99 \%$. Ketika penurunan arus $70 \mathrm{kV} 5 \mathrm{mAs}$ nilai deviasi $0.47 \%$. Dengan melakukan peningkatan pada tegangan dan arus $80 \mathrm{kV}$ 20mAs nilai deviasi yang dihasilkan meningkat $0.89 \%$.

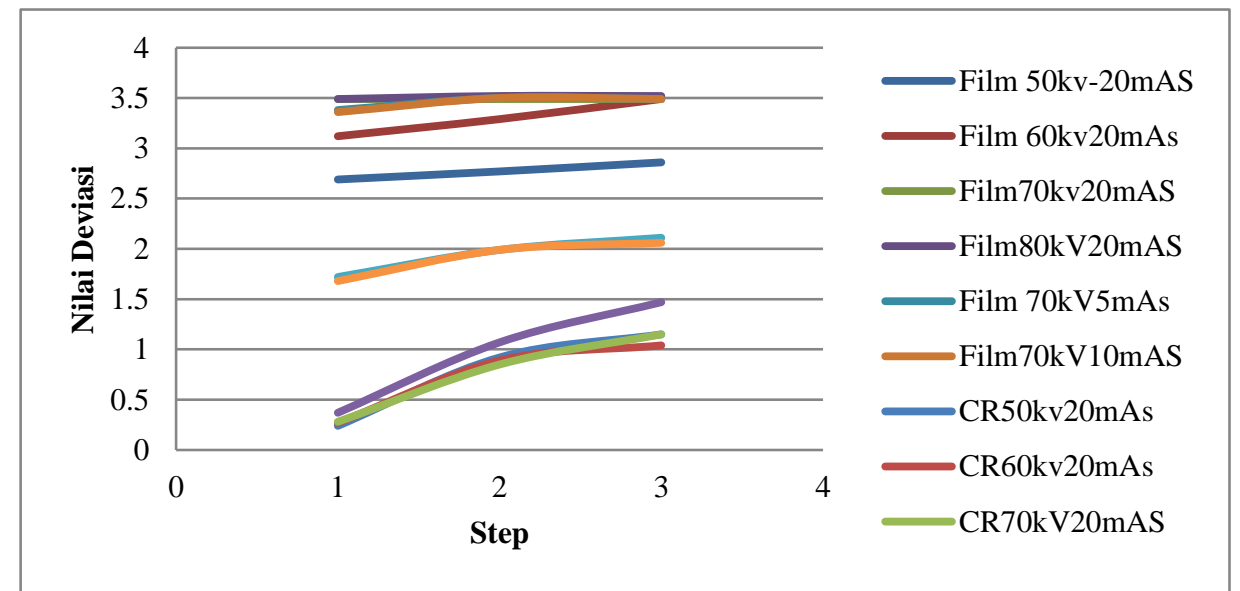

GAMBAR 4. Hasil pengukuran pada tulang perbandingan hasil nilai deviasi antara film dengan CR.

Penggunaan faktor eksposi yang tinggi mengakibatkan daerah straight line tidak terlihat jika faktor eksposi berubah maka kurva karakteristik yang dihasilkan juga akan berubah [8]. Penggunaan faktor eksposi tinggi pada pasien langsung tidak dianjurkan Satu hal yang perlu ditekankan bahwa sekecil apapun dosis radiasi yang diterima tubuh memiliki potensi yang memunculkan efek yang berdampak negatif bagi kesehatan. Oleh karena itu, ICRP menganjurkan dipenuhinya tiga azas dalam pemanfaatan radiasi, baik untuk keperluan medis maupun kegiatan lainnya. Ketiga azas tersebut adalah justifikasi (pembenaran) yang mensyaratkan agar pemanfaatan radiasi itu memberikan manfaat yang besar, optimisasi yang menganjurkan agar penerimaan dosis oleh tubuh diusahakan serendah mungkin dengan biaya yang dapat dipertanggungjawabkan secara ekonomi dan yang terakhir adalah pembatasan dosis yang mensyaratkan agar penerimaan dosis radiasi oleh tubuh tidak melampaui nilai batas yang telah ditetapkan [9].

Berdasarkan Peraturan Kepala BAPETEN No. 8 Tahun 2011 tentang Keselamatan Radiasi Dalam Penggunaan Pesawat Sinar-X Radiologi Diagnostik dan Intervensional bahwa penerapan optimisasi proteksi dan keselamatan radiasi harus diupayakan agar pasien, petugas radiasi maupun pendamping pasien menerima dosis radiasi serendah mungkin sesuai dengan yang diperlukan untuk mencapai tujuan diagnostik [10].

\section{KESIMPULAN}

Dari hasil penelitian dan pembahasan yang telah dilakukan uji banding citra imaging dengan film terhadap CR, dapat disimpulkan bahwa variasi faktor eksposi mempunyai pengaruh yang kuat sekali dan signifikan terhadap citra imaging film dan mempunyai pengaruh yang tidak signifikan terhadap citra imaging CR. Untuk kontur sebaran nilai densitas semakin besar faktor eksposi maka nilai densitas yang dihasilkan akan 
meningkat dan mencapai nilai ussefull. Dari pengujian 2 variasi nilai eksposi rendah dan tinggi, penulis mendapatkan bahwa pada CR faktor eksposi rendah nilai densitas yang dihasilkan tidak signifikan kenaikannya. Dengan faktor eksposi yang tinggi CR menghasilkan nilai usefull density yang bagus 0.25 sampai 2 . Tapi hal ini berbanding terbalik pada film dengan otomatis, data yang dihasilkan tidak mampu menampilkan hasil gambaran hingga faktor eksposi tertinggi. Hasil gambaran yang didapat gelap dan objek yang digunakan tidak terlihat.

\section{REFERENSI}

[1] Balinger, Philip.W, Eugene D Frank. 2005. Merrill's Atlas of Radiographic Positions and Radiologic Procedures. (10th ed.). St. Louis: Elsevier Science Health Science Division

[2] Takano, Masao (auth.), Yukio Tateno, Takeshi Iinuma, Masao Takano (eds.). 1987. Computed Radiography. Tokyo: Springer.

[3] Suyatno, F. 2008. Aplikasi radiasi sinar-x di bidang kedokteran untuk menunjang kesehatan masyarakat. Prosiding seminar nasional IV SDM teknologo nuklir. Yogyakarta, 25-26 Agustus 2008. ISSN 1978-0176.

[4] Arif Fahmi1, K. Sofjan Firdausi2, Wahyu Setia Budi2. Pengaruh faktor eksposi pada pemerikasaan Abdomen terhadap kualitas radiograf dan Paparan radiasi menggunakan computed Radiography. Laboratorium Fisika Atom \& Nuklir, Jurusan Fisika FMIPA UNDIP

[5] DR. Ningtias, S. Suryono, Susilo. Pengukuran kualitas citra digital Computed Radiography menggunakan program pengolahan citra. Jurnal Pendidikan Fisika Indonesia 12 (2) (2016) 161-168

[6] Bushong, steward C, 2003, Radiologic Scince For technologist Physics, Biologi and Protection (4th ed), C.V. mosby CO. Missoure.

[7] Rahman, Nova. 2009. Radiofotografi. Padang: Universitas Baiturrahmah

[8] Desai, N., Singh, A., and Valentino, D. J. (2010). Practical Evaluation of Image Quality in Computed Radiographic (CR)

[9] ANONIM.: International Commission On Radiological Protection, ICRP (1990) publication 60, Recommendations of the International Commission on Radiological Protect- ion

[10] ANONIM : Peraturan Kepala Badan Pengawas Tenaga Nuklir Nomor 8 Tahun 2011 Tentang Keselamatan Radiasi Dalam Penggunaan Pesawat Sinar-X Radiologi Diagnostik Dan Intervensional. 